\title{
GEOCRONOLOGIA APLICADA AO JAZIMENTO DE COBRE DE MANTOS BLANCOS, NORTE DO CHILE
}

\author{
C.C.G.Tassinari ${ }^{1}$ \\ F.Munizaga ${ }^{2}$ \\ R.Ramirez ${ }^{3}$ \\ R.Drake 4 \\ M.Zentilli ${ }^{5}$
}

O trabalho objetiva determinar a idade e as fontes das mineralizações de cobre do jazimento estratiforme do tipo "manto" de Mantos Blancos, que situa-se a $40 \mathrm{~km}$ a nordeste da cidade de Antofagasta no norte do Chile.

O jazimento encontra-se encaixado em uma sequência de rochas vulcânicas ácidas jurássicas, intrudida por um corpo dacftico de natureza sub-vulcânica e cortada por vários diques andesíticos.

A mineralização é constituída por óxidos e sulfetos de cobre, principaimente calcosina, bornita, calcopirita e covelina, que se apresentam como corpos irregulares pseudoestratiformes sub-paralelos à estratificação das rochas encaixantes. As rochas vulcânicas da região mineralizada encontram-se alteradas hidrotermalmente através de metassomatismo sódico.

Duas isócronas $\mathrm{Rb}-\mathrm{Sr}$ em rocha total, uma para rochas encaixantes com alteração hidrotermal incipiente e outra para as rochas fortemente alteradas indicaram respectivamente as idades de $175 \pm 5 \mathrm{Ma}$. (r.i. $=0,7052 \pm 0,0001)$ e $149 \pm 2 \mathrm{Ma}$. (r.i. $=0,7055 \pm 0,0001$ ). $\mathrm{O}$ primeiro dado é

\footnotetext{
${ }^{1}$ Centro de Pesquisas Geocronológicas e Departamento de Geologia Geral, Instituto de Geociências, USP. 2 Departamento de Geologia, Universidade do Chile, Chile.

${ }^{3}$ Cia.Minera Alglo-América-Chile, Chile.

${ }^{4}$ Institute of Human Origin, Berkeley, USA.

5 Dept.Geology Falhousie, Halifax, Canadá.
} 
interpretado como próximo da idade de formação do vulcanismo e o mais jovem como a época da alteração hidrotermal. Idades $\mathrm{K}-\mathrm{Ar}$ e ${ }^{40} \mathrm{Ar} /{ }^{39} \mathrm{Ar}$ em minerais e rocha total indicaram para esta rochas idades próximas a $146 \mathrm{Ma}$. e entre 125 e $110 \mathrm{Ma}$., sendo a primeira idade admitida como a época de resfriamento do evento hidrotermal e o intervalo de idades de 125 a $110 \mathrm{Ma}$. relacionados a diques e a rochas cloritizadas, associadas a eventos magmáticos e/ou térmicos mais jovens que ocorreram na área.

Calcitas relacionadas às mineralizações forneceram razões ${ }^{87} \mathrm{Sr} /{ }^{86} \mathrm{Sr}$ entre 0,7057 e 0,7059, interpretadas como razão inicial de $\mathrm{Sr}$ dos fluídos mineralizantes, que coincidem aproximadamente com a razão inicial das rochas alteradas, o que permite relacionar a mineralização com os processos de alteração hidrotermal.

As rochas encaixantes isentas de alteração, que ocorrem fora da área da mina, indicaram idade isocrônica $\mathrm{Rb}-\mathrm{Sr}$ de $183 \pm 14 \mathrm{Ma}$. com razão inicial de 0,7032. Calculando a razão ${ }^{87} \mathrm{Sr} /{ }^{86} \mathrm{Sr}$ destas rochas há $150 \mathrm{Ma}$ atrás (época da mineralização) obtém-se o valor de 0,7041, mais balxo que a razão inicial da mineralização. Como durante o processo de interação fluido-rocha encalxante ocorre a homogeneização isotópica de $\mathrm{Sr}$ esperar-se-ia a mesma razão ${ }^{87} \mathrm{Sr} /{ }^{86} \mathrm{Sr}$.

Portanto, para que a razão inicial das mineralizações seja de 0,7056 é necessário que os fluidos hidrotermais tenham além da interação com as rochas encaixantes, sofrido um processo de mistura com soluções de razões ${ }^{87} \mathrm{Sr} /{ }^{86} \mathrm{Sr}$ mais elevadas, como por exemplo a água do mar, já que próximo a Mantos Blancos ocorrem calcários jurássicos que apresentavam na época um valor de 0,7093 .

Como a composição isotópica de $\mathrm{C}$ e $\mathrm{O}\left(\delta^{13} \mathrm{C}_{\mathrm{PDB}}=-4,95\right.$ a $-5,42$ e $\delta^{18} \mathrm{~S}_{\mathrm{SMOW}}$ $=+12,6 \mathrm{a}+16,4)$ não suportam uma origem principalmente pela água do mar, uma hipótese alternativa seria que vários tipos de água contribuíram em proporções variáveis na composição dos fluidos, que teriam percolado e/ou se originado em meio às rochas vulcano-sedimentares de composição isotópica de $\mathrm{Sr}$ mais radiogênica, que seriam a fonte do cobre para as mineralizações. 